\title{
Burden of Dyspepsia in Rural and Urban Asia
}

TO THE EDITOR: I have read with great interest the recently published article "Economic impact of dyspepsia in rural and urban Malaysia: a population-based study." ${ }^{1}$ This study tried to estimate the costs of dyspepsia in rural and urban population in Malaysia, a multi-ethnic Asian country with variable ethnic distribution between urban and rural population. The authors noticed that the prevalence of dyspepsia and its associated economic impact are greater in an urban compared to a rural setting. The absolute cost to dyspepsia per 1,000 population per year was estimated at USD14,816.10 and USD59,282.20 in the rural and urban populations respectively. Though the cost is far less than the cost of functional dyspepsia in Western countries, dyspepsia remains considerable burden to the country. ${ }^{2,3}$ The authors should be congratulated for completing this large-scaled epidemiology study, which contributes much to the scanty knowledge regarding the economic impact of functional gastrointestinal disorder in Asia-Pacific region. Nevertheless, I would like to raise up 2 concerns.

First of all, it is not surprising that the economic impact for dyspepsia would be much higher in the urban than rural area, which might be resulted from the differences of the demographic characteristics and availability of medical resources between the rural and urban population. However, the true impact of (uninvestigated) dyspepsia could have been known if age-, sex- and co-mobidity matched non-dyspepsia subjects had been enrolled as the control group. With this approach, the extra-cost incurred from dyspepsia could have been obtained. And the differences in economic impact between the subjects with and without dyspepsia, no matter in urban or rural region, would have been more clear. The current study was a population study by investigating the gastrointestinal symptoms in over 2,000 residents in both the rural and urban Malaysia. Thus, the authors might be able to re-analyze the data to give us a better overview of the economic impact of dyspepsia in rural and urban Malaysia.

Secondary, for the dyspeptic patients in Malaysia, in both rural and urban region, antacid remained the mainstream of treatment. Very few patients in this series were given histamine 2 (H2) blocker or proton pump inhibitor (PPI). Surprisingly, the price of $\mathrm{H} 2$ blocker in Malaysia is even lower than that of antacid. Current meta-analysis has already shown that the efficacy of antacid is no better than placebo, while both $\mathrm{H} 2$ blocker and PPI beat the placebo. ${ }^{4}$ And PPI is suggested as the drug of choice for functional dyspepsia according to the current management guidelines. 5,6 Then, people may raise a question: "why not give the dyspeptic patients with the more effective and cheaper drug like H2 blocker, instead of the antacid?" Furthermore, the satisfactory response under the treatment of antacid and the role of Helicobacter pylori of in these dyspeptic patients may be the unressolved, but important, issues in the current paper.

\section{Ching-Liang Lu \\ Division of Gastroenterology, Department of Medicine, Taipei Veterans General Hospital; and Institute of Brain Science, National Yang-Ming University, Taipei, Taiwan}

1. Mahadeva S, Yadav H, Everett SM, Goh LK. Economic impact of dyspepsia in rural and urban Malaysia: a population-based study. J Neurogastroenterol Motil 2012;18:43-57.

2. Moayyedi P, Mason J. Clinical and economic consequences of dyspepsia in the community. Gut 2002;50(suppl 4):iv10-iv12.

3. Brook RA, Kleinman NL, Choung RS, Melkonian AK, Smeeding JE, Talley NJ. Functional dyspepsia impacts absenteeism and direct and indirect costs. Clin Gastroenterol Hepatol 2010;8:498-503.

4. Moayyedi P, Soo S, Deeks J, Delaney B, Innes M, Forman D. Pharmacological interventions for non-ulcer dyspepsia. Cochrane Database Syst Rev 2006;(4):CD001960.

5. Talley NJ. American Gastroenterological Association medical position statement: evaluation of dyspepsia. Gastroenterology 2005;129:17531755.

6. Miwa H, Ghoshal UC, Fock KM, et al. Asian Consensus Report on Functional Dyspepsia. J Gastroenterol Hepatol Published Online First: 6 Dec 2011. doi: 10.1111/j.1440-1746.2011.07037.x

Conflicts of interest: None. 